\title{
Synthesis and Immobilization of $\beta$-Formyl-meso-nitrophenyl- triphenylporphyrin and Its Copper Complex on Polyvinyl Alcohol
}

\author{
Elena V. Alopina, ${ }^{a}$ Tatyana A. Ageeva, ${ }^{a}$ Alexey V. Lyubimtsev, ${ }^{a}$ \\ Oleg Yu. Kuznetsov ${ }^{c}$, Sergei A. Syrbu, ${ }^{a}$ and Oscar I. Koifman ${ }^{a, b}$ \\ anstitute of Macroheterocycles, Ivanovo State University of Chemistry and Technology, 153000 Ivanovo, Russia \\ ${ }^{\mathrm{b}}$ Institute of Solution Chemistry of Russian Academy of Sciences, 153045 Ivanovo, Russia \\ 'Ivanovo State Medical Academy "Roszdrava", 153000 Ivanovo, Russia \\ ${ }^{\circledR}$ Corresponding authorE-mail: alopina@mail.ru
}

\begin{abstract}
An efficient synthesis of the free base (4a) and copper(II) complex (4b) of meso-tetraphenylporphyrin having both nitroand formyl-groups at the periphery of the tetrapyrrole macroheterocycle is reported. Elemental analysis, ${ }^{1} H \mathrm{NMR}$, $I R$ - and electronic absorption spectroscopy were used to confirm a structure of obtained compounds. In order to obtain water-soluble compounds, porphyrins $\mathbf{4 a}$ and $\mathbf{4 b}$ were immobilized on polyvinyl alcohol and their antibacterial effect was investigated. Metal porphyrin-polymer system shows the highest antibacterial effect.
\end{abstract}

Keywords: meso-Tetraphenylporphyrin, synthesis, metal complex, porphyrin, polyvinyl alcohol, immobilization, antibacterial effect.

\section{Introduction}

Metalloporphyrins and their analogues are effective catalysts for many chemical reactions. ${ }^{[1]}$ However, most of these compounds are insoluble in water. At the same time, all natural porphyrin metal complexes perform their biologically important functions in aqueous environments. One way to give the solubility of the tetrapyrrole macroheterocycles and their metal complexes, and at the same time, to exclude the possibility of associates formation in solutions is their immobilization on the water-soluble polymers. Porphyrins immobilized on various polymeric carriers (PPIm), are used for a multitude of problems in biotechnology, engineering, medicine. ${ }^{[2,3]}$ Intensive studies of the possible use of immobilized metal porphyrin as organic semiconductors, polymer films with high electrical conductivity, lightsensitive materials for recording holographic images, sensors for oxygen and toxic gases, highly selective catalysts, etc. [4] Currently, one of the most promising applications of PPIm and their complexes are medicine and pharmacology. [5-7] The complex nature of the use of porphyrins and their metal complexes immobilized on polymer-carriers, stimulate increased interest in the synthesis and study of physicochemical properties of PPIm.

One of the easiest ways to attach the porphyrin to watersoluble polymer is a covalent immobilization of porphyrin formyl-derivatives and their metal complexes on polyvinyl alcohol using the acetylation reaction. ${ }^{[8]}$

Previously, we developed a method of immobilization of 2-formyl-5,10,15,20-tetraphenylporphyrin copper(II) (CuTPP-CHO) on polyvinyl alcohol. ${ }^{[9]}$ However, the obtained water-soluble PPIm with CuTPP-CHO did not show significant biological activity, and the compounds did not have inhibitory effect on the development of bacterial test cultures (both gram positive and gram-negative bacterial strains).
It is well known, that effect of the nitro group has a high oxidative reactivity. Some nitro-containing compounds (nitrofurans, nitroimidazoles) are effective antibacterial agents and are used extensively to combat anaerobic and protozoal infections. ${ }^{[10]}$

To create a porphyrin-polymer materials with significant biological activity we have synthesized the water-soluble PPIm on polyvinyl alcohol containing meso-nitrophenyl- $\beta$ formylporphyrin $\mathrm{H}_{2}$ TPP-CHO(NO ${ }_{2}$ (4a), and its copper(II) complex, CuTPP-CHO(NO 2$)(4 b)$.

\section{Experimental}

\section{General}

Infrared spectra were recorded using an Infrared Fourier Avatar 360 (Nicolet) spectrometer. Electronic absorption spectra were recorded on a scanning spectrophotometer UV-VIS Lambda 20 and a Shimadzu UV 2550 PC UV-VIS-scanning spectrophotometer. All measurements were performed in standard $1 \mathrm{~cm}$ quartz cells.

${ }^{1} \mathrm{H}$ NMR spectra were recorded on a Bruker AC-400 (400 MHz) spectrometer. Deuteriochloroform was used as the solvent with trimethylsilane as an internal standard unless otherwise stated.

$\mathrm{N}, \mathrm{N}$-Dimethylformamide, ethylene glycol, sulfuric acid, acetone, chloroform, marked "analytical grade" were used. $N, N$-Dimethylformamide, chloroform were routinely dried and redistilled prior to use. Polyvinyl alcohol (PVA) with degree of polymerization 600 , with molecular weight 33000 , the content of hydroxyl groups - $33 \mathrm{mg} \mathrm{KOH} / \mathrm{g}$ PVA has been determined from the viscosity using a capillary viscometer glass type of VPJ-2 (d $=237 \mathrm{~mm}$ ) at $25^{\circ} \mathrm{C}$. The values of characteristic viscosity used to calculate the molecular weight of PVA.

\section{Synthesis}

2-Formyl-5,10,15,20-tetraphenylporphyrin, $\mathrm{H}_{2}$ TPP-CHO (3) and 2-formyl-10(15)-(4'-nitrophenyl)-5,15(10),20-triphenyl- 
porphyrins, $\mathrm{H}_{2} \mathrm{TPP}-\mathrm{CHO}\left(\mathrm{NO}_{2}\right)$ (4a), were obtained according to the procedure described earlier ${ }^{[11]}$ from the corresponding $\mathrm{Cu}^{\mathrm{II}}$ complexes $\mathbf{1 b}$ and $\mathbf{2 b}$.

Nitration. Sodium nitrite $(1 \mathrm{mmol})$ was added at room temperature to a solution of $1 \mathrm{mmol}$ of porphyrin $1 \mathbf{a}$ or $\mathbf{3}$ in $10 \mathrm{ml}$ of trifluoroacetic acid (TFA). The reaction mass was stirred at room temperature for $15 \mathrm{~min}$ and poured into ice water. The mixture was neutralized with aqueous ammonia. The precipitate was filtered, washed with water, dried under vacuum at $60^{\circ} \mathrm{C}$. The product was chromatographed on silica gel column using chloroform as an eluant.

5-(4'-Nitrophenyl)-10,15,20-triphenylporphyrin $\quad$ (2a): $\quad{ }^{1} \mathrm{H}$ $\operatorname{NMR}\left(\mathrm{CDCl}_{3}\right) \delta$ ppm: $8.88(\mathrm{~d}, 2 \mathrm{H}) ; 8.85(\mathrm{~s}, 4 \mathrm{H}) ; 8.72(\mathrm{~d}, 2 \mathrm{H}) ; 8,62$ $(\mathrm{d}, 2 \mathrm{H}) ; 8.38(\mathrm{~d}, 2 \mathrm{H}) ; 8.20(\mathrm{~d}, 6 \mathrm{H}) ; 7.83-7.70(\mathrm{~m}, 9 \mathrm{H}) ;-2,81$ (s, 2H, -NH). UV-vis $\left(\mathrm{CHCl}_{3}\right) \lambda_{\text {max }}$ nm (lge): 515 (4.31), 552 (4.00), 591 (3.82), 647 (3.65).

2-Formyl-10(15)-(4'-nitrophenyl)-5,15(10),20-triphenylporphyrin (4a): ${ }^{1} \mathrm{H}$ NMR $\left(\mathrm{CDCl}_{3}\right) \delta \mathrm{ppm}: 9.40(\mathrm{~s}, 1 \mathrm{H}) ; 9.20(\mathrm{~s}, 1 \mathrm{H})$; 9.05-8.70 (m, 6H); 8.63 (d, 2H); 8.37 (d, 2H); 8.22 (d, 2H); 8.20$8.16(\mathrm{~m}, 4 \mathrm{H}) ; 7.89-7.69(\mathrm{~m}, 9 \mathrm{H}),-2.57(\mathrm{~s}, 2 \mathrm{H})$. UV-vis $\left(\mathrm{CHCl}_{3}\right)$ $\lambda_{\max } \mathrm{nm}(\lg \varepsilon): 526$ (4.22), 567 (3.88), 605 (3.75), 663 (3.85).

\section{Immobilization of $4 \boldsymbol{a}$ and $\mathbf{4 b}$ on Polyvinyl Alcohol}

Immobilization of the porphyrins $\mathbf{4 a}$ and $\mathbf{4 b}$ on the PVA was carried out by the described earlier method. ${ }^{[9]}$ Immobilization product with $\mathrm{H}_{2}$ TPP-CHO(NO $\left(\mathrm{NO}_{2}\right)$ : mass content of the porphyrin was $1.83 \%$, molar degree of porphyrin immobilization - 0.109. UV-vis $\left(\mathrm{H}_{2} \mathrm{O}\right) \lambda_{\max } \mathrm{nm}(\lg \varepsilon): 417$ (3.99), 542 (3.16). Immobilization product with copper(II) complex CuTPP-CHO(NO $\left.\mathrm{NO}_{2}\right)$ : mass content of the porphyrin was $1.85 \%$, molar degree of porphyrin immobilization 0.11. UV-vis $\left(\mathrm{H}_{2} \mathrm{O}\right) \lambda_{\text {max }} \mathrm{nm}(\mathrm{lg} \varepsilon): 411$ (3.97), 545 (3.01).

\section{Determination of the Antibacterial Action of PPIm}

To assess the biological activity of immobilizats used diffuse method for estimating the influence of antibiotics on the test cultures of microorganisms: Escherichia coli M-17, Staphylococcus aureus and Candida albicans. The test cultures of microorganisms were grown on the slant. Then washed cultures were added to saline solution to a concentration of 10 Units using a standard turbidity of
MacFarland. Then $1 \mathrm{ml}$ of the resulting microbial suspension was combined with $9 \mathrm{ml}$ of culture medium (MPB for E.coli culture and sugar broth for S.aureus and C.albicans). Sample tubes were placed in an incubator at $37^{\circ} \mathrm{C}$ for 24 hours.

Then the ratios of the light transmission control culture of microbes were determined and the test sample using a colorimeter photovoltaic concentration CK-2 with $5 \mathrm{ml}$ cuvette at a wavelength of $540 \mathrm{~nm}$. Based on these data the biological activity of microbial cultures, growing 24 hours in the presence of the test immobilization sample, was calculated relatively the growth of control microbial culture.

\section{Results and Discussion}

\section{Synthesis}

Synthesis of porphyrins 4a was performed: a) by nitration of 5,10,15,20-tetraphenylporphyrin $\mathbf{1 a}$ with following formylation; b) by nitration of 2-formyl5,10,15,20-tetraphenylporphyrin 3 (Scheme 1).

Nitration of porphyrins $\mathbf{1 a}$ and $\mathbf{3}$ was carried out using various nitration systems. It is shown that the most efficient nitration system is a mixture of TFA- $\mathrm{NaNO}_{2}$. Using this system the degree of nitration of meso-tetraphenylporphyrins can be easily controled. 5-(4'-Nitrophenyl),10,15,20triphenylporphyrin (2a) was synthesized by nitration of $\mathbf{1}$, yielding mainly the target product. Nitration of 2-formyl5,10,15,20-tetraphenylporphyrin (3) leads to a mixture of isomeric nitrophenylporphyrins $\mathbf{4 a}$, that could not be separated by column and preparative chromatography.

Formylation of 5,10,15,20-tetraphenylporphyrin (1a) and its mono-nitroderivative $\mathbf{2} \mathbf{a}$ was performed by a known method of Vilsmeier ${ }^{[1]}$ from the corresponding copper complexes $\mathbf{1 b}$ and $\mathbf{2 b}$.

The resulting 2-formyl,10(15)-(4'-nitrophenyl)5,15(10),20-triphenylporphyrins $\mathbf{4 a}$ and its copper(II) complexes $\mathbf{4 b}$ were characterized by UV-vis, IR and ${ }^{1} \mathrm{H}$ NMR (only for 4a) spectroscopy.

The IR spectra of porphyrins $\mathbf{4 a}$ reveal the band of stretching vibrations of the $\mathrm{N}-\mathrm{O}$ coupling of nitro group at

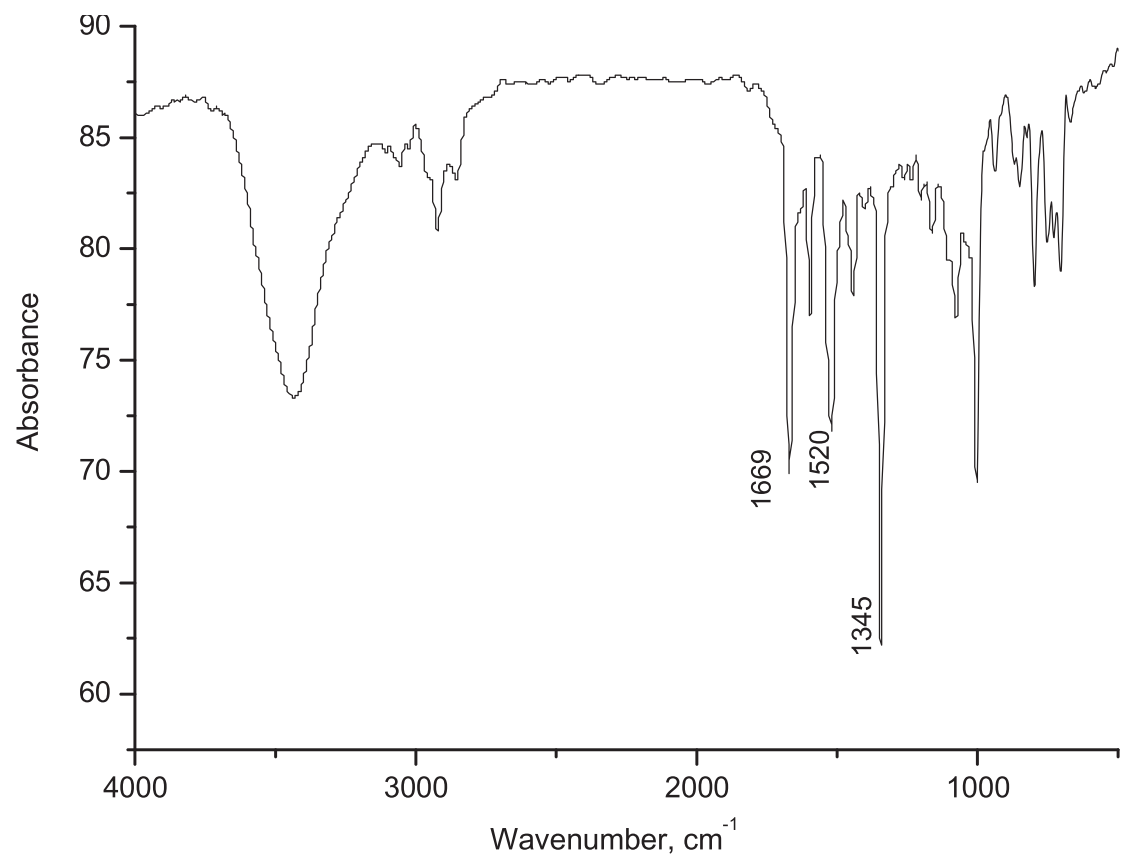

Figure 1. IR spectra of porphyrin $4 a$. 


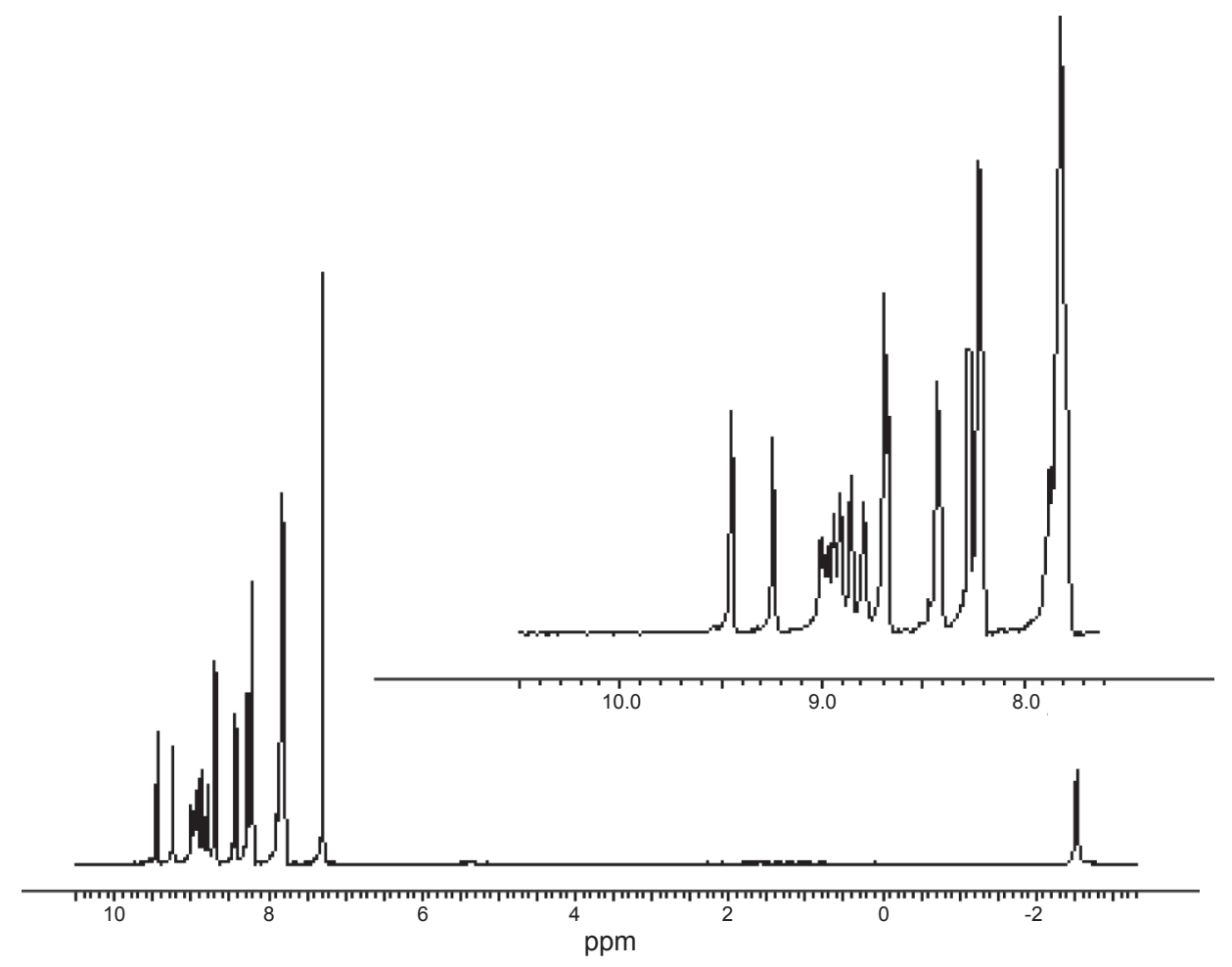

Figure 2. ${ }^{1} \mathrm{H}$ NMR spectrum of porphyrin $4 \mathbf{a}$.
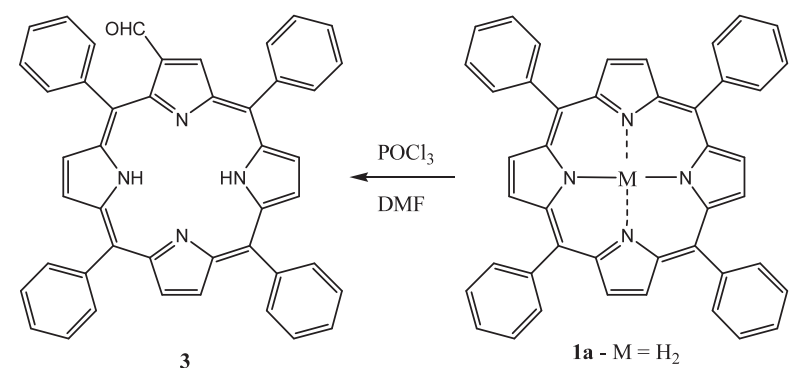

1a $-\mathrm{M}=\mathrm{H}_{2}$

$\mathbf{1 b}-\mathrm{M}=\mathrm{Cu}$<smiles>CC(C)[N+](=O)[O-]</smiles>

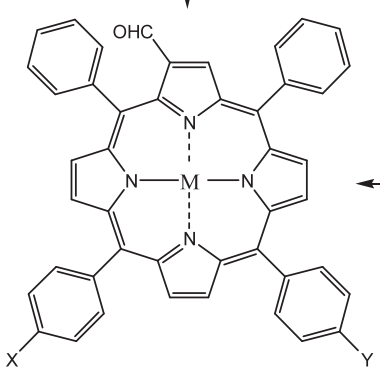

4a $-\mathrm{X}=\mathrm{NO}_{2}, \mathrm{Y}=\mathrm{H}\left(\right.$ or $\left.\mathrm{Y}=\mathrm{NO}_{2}, \mathrm{X}=\mathrm{H}\right), \mathrm{M}=\mathrm{H}_{2}$ 4b $-\mathrm{X}=\mathrm{NO}_{2}, \mathrm{Y}=\mathrm{H}$ ( or $\mathrm{Y}=\mathrm{NO}_{2}, \mathrm{X}=\mathrm{H}$ ), $\mathrm{M}=\mathrm{Cu}$

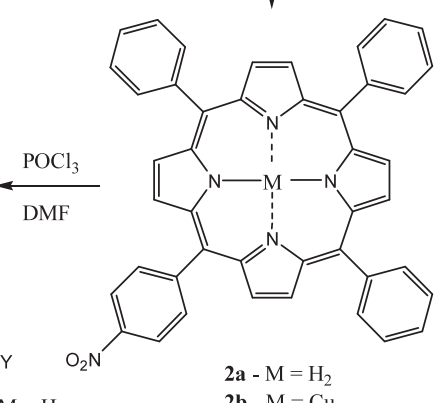

2b $-\mathrm{M}=\mathrm{Cu}$

Scheme 1.

1345 and $1520 \mathrm{~cm}^{-1}$, and the band of stretching vibrations of the $\mathrm{C}=\mathrm{O}$ coupling of formyl group at $1669 \mathrm{~cm}^{-1}$ (Figure 1).

The presence of formyl and nitro groups leads to a change in the symmetry of the molecule, what is revealed in the ${ }^{1} \mathrm{H}$ NMR spectrum (Figure 2).

In particular, the signals of six $\beta$-protons appear as multiplet at $c a .9 \mathrm{ppm}$. The signal of the proton adjacent to the formyl group appears at $9.5 \mathrm{ppm}$. The signals of the protons of unsubstituted phenyl fragments do not undergo significant changes from baseline tetraphenylporphyrin 1a and its mono-nitroderivative $\mathbf{2 a}$.

\section{Immobilization}

In order to obtain water-soluble porphyrin-polymer a covalent immobilization of the synthesized porphyrins $\mathbf{4 a}$ and $\mathbf{4 b}$ on the polyvinyl alcohol in aprotic solvent (DMF) was carried out (Scheme 2). The obtained PPIm are intensely colored solid polymeric products, which are soluble in water.

Evidence of covalent bonding formyl porphyrins with PVA is invariance contents of PPIm in multiple reprecipitations from solutions and long-term extraction, controlled by spectrophotometric method.

The mass content of the immobilized porphyrin and the mol degree of immobilization (the number of moles of porphyrin per $100 \mathrm{~mol}$ of elementary units of media) was determined by UV-visible absorption spectra.

The character of electronic absorption spectra of the synthesized PPIm is similar to that of the initial porphyrin. However, all UV-visible absorption spectra of PPIm were shifted to short-wavelength region compared with those of initial porphyrin $\left(\mathrm{H}_{2} \mathrm{TPP}-\mathrm{CHO}\left(\mathrm{NO}_{2}\right)\right.$ and $\mathrm{Im}-\mathrm{H}_{2} \mathrm{TPP}-$ $\mathrm{CHO}\left(\mathrm{NO}_{2}\right)$ : Soret bands - 442 and $417 \mathrm{~nm} ; Q$ bands - 543 and $523 \mathrm{~nm}$, respectively (Figure 3); $\mathrm{CuTPP}-\mathrm{CHO}\left(\mathrm{NO}_{2}\right)$ and Im-CuTPP-CHO $\left(\mathrm{NO}_{2}\right)$ : Soret bands - 430 and $411 \mathrm{~nm} ; Q$ bands - 551 and $545 \mathrm{~nm}$, respectively (Figure 4)).

The shifts toward short-range in both metal-free pophyrin $\mathrm{H}_{2} \mathrm{TPP}-\mathrm{CHO}\left(\mathrm{NO}_{2}\right)$ and coper(II) pophyrin CuTPP$\mathrm{CHO}\left(\mathrm{NO}_{2}\right)$ spectra are in agreement with expectation, as electron-withdrawing substituents $\mathrm{CHO}, \mathrm{NO}_{2}$ (partly) with PVA tend to stabilize the MOs. And in the case of metal complexes, a slight shift in comparison with metal-free pophyrin $\mathrm{H}_{2}$ TPP-CHO $\left(\mathrm{NO}_{2}\right)$ is observed. 


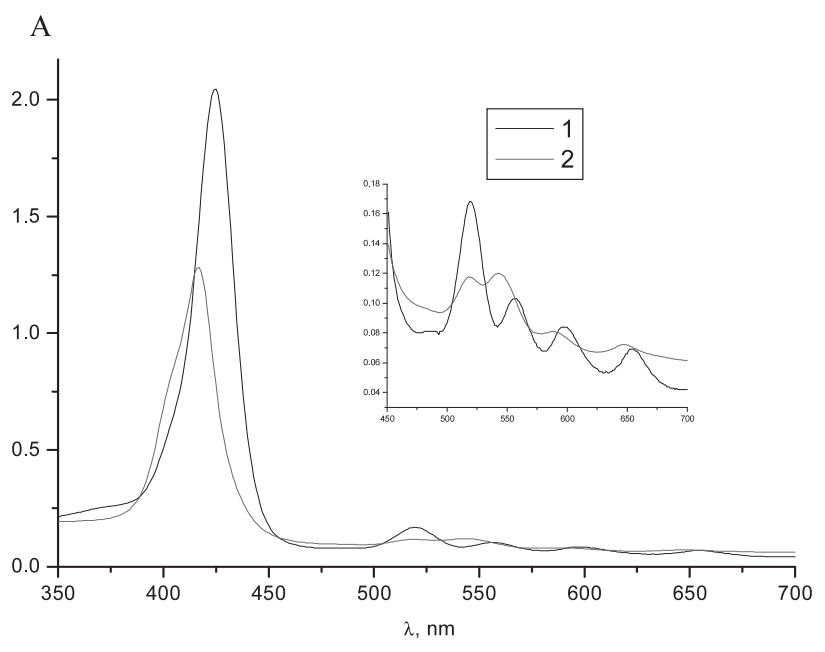

Figure.3. UV-vis spectra of $\mathrm{H}_{2} \mathrm{TPP}-\mathrm{CHO}\left(\mathrm{NO}_{2}\right)$ in DMF (1) and PPIm with $\mathrm{H}_{2}$ TPP-CHO(NO 2$)$ in $\mathrm{H}_{2} \mathrm{O}(2)$.

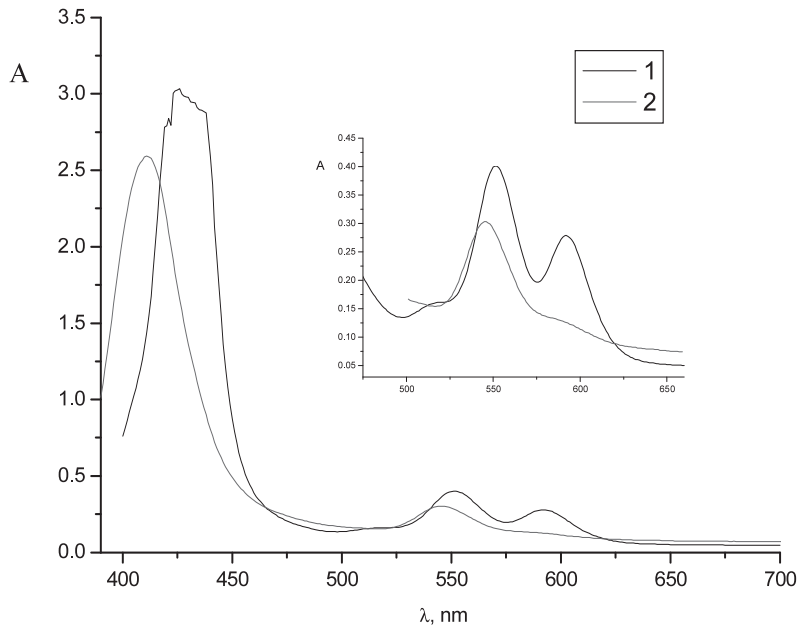

Figure.4. UV-vis spectra of CuTPP-CHO $\left(\mathrm{NO}_{2}\right)$ in DMF (1) and of PPIm with CuTPP-CHO $\left(\mathrm{NO}_{2}\right)$ in $\mathrm{H}_{2} \mathrm{O}(2)$.

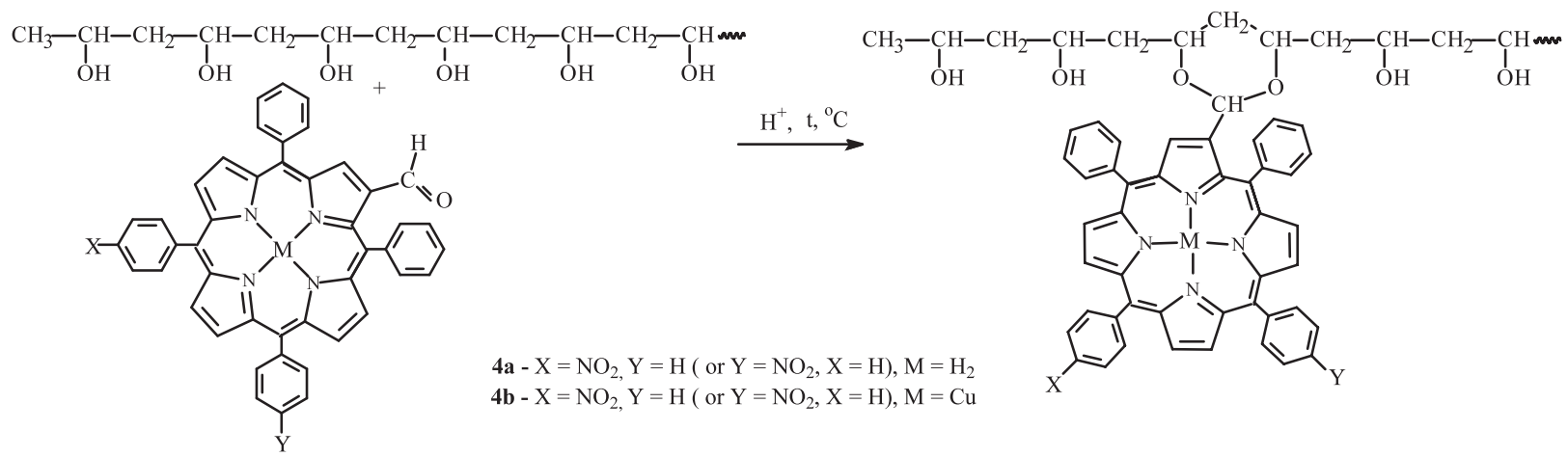

Scheme 2.

Table 1. The effect on the cure of microorganisms, $\%$.

\begin{tabular}{|c|c|c|c|c|c|c|c|}
\hline \multirow{2}{*}{$\begin{array}{c}\text { Culture of } \\
\text { microorganisms }\end{array}$} & \multicolumn{5}{|c|}{ PPIm with CuTPP-CHO $\left(\mathrm{NO}_{2}\right), 10^{-3} \mathrm{~mol} / 1$} & \multicolumn{2}{|c|}{$\begin{array}{l}\text { PPIm with } \mathrm{H}_{2} \text { TPP- } \\
\mathrm{CHO}\left(\mathrm{NO}_{2}\right), 10^{-3} \mathrm{~mol} / 1\end{array}$} \\
\hline & 0.35 & 0.5 & 0.98 & 2.33 & 4.46 & 1.76 & 3.06 \\
\hline Bacterial culture & inhibition & inhibition & inhibition & growth & growth & growth & growth \\
\hline E. coli & 18 & 21 & 16 & 28 & 0 & 14 & 28 \\
\hline Staphylococcus & inhibition & inhibition & inhibition & inhibition & growth & growth & inhibition \\
\hline aureus & 26 & 34 & 36 & 39 & 0 & 5 & 3 \\
\hline Fungal culture & inhibition & inhibition & growth & growth & growth & inhibition & growth \\
\hline Candida albicans & 21 & 28 & 3 & 0 & 29 & 10 & 20 \\
\hline
\end{tabular}

\section{Determination of Antibacterial Action}

The results of antibacterial activity determination of the samples are listed in Table 1. So, the metal in the porphyrin core has a significant effect on the inhibition of cultures. Moreover, metal-free PPIm complex facilitates the growth of tested cultures most of all.

Antimicrobial effect may be caused also by reduction of nitro groups of PPIm. In the case of metal-free porphyrin species, at low concentrations of the solution the slower growth of E.coli cultures and even inhibition of fungal culture of Candida albicans are observed; at the same time Staphylococcus aureus is subjected to the opposite effect. Probably, the observed inhibition at low PPIm concentration occurs due to high oxidation reaction ability of nitro group, acting both on the proteins of cytoplasmic membrane and the protein complexes within cells of microorganisms.

The PPIm solution concentration influences greatly on the antibacterial activity of the studied test cultures. For example, $0.5 \cdot 10^{-3} \mathrm{M}$ Im-porphyrin-CuTPP-CHO $\left(\mathrm{NO}_{2}\right)$ has an inhibitory effect on growth in culture E. coli (36\%). At higher concentration of the solution the opposite effect is observed (Figure 5). 


\section{E.coli}

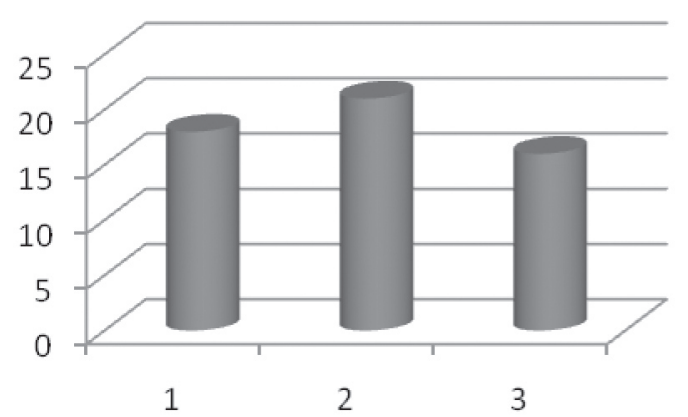

Figure 5. Effect of immobilized CuTPP-CHO(NO 2$)$ on the E.coli growth intensity at various concentrations of PPIm: $0.35 \cdot 10^{-3} \mathrm{M}$ (1), $0.5 \cdot 10^{-3} \mathrm{M}(2)$ and $0.98 \cdot 10^{-3} \mathrm{M}(3)$.

In the case of Staphylococcus aureus the sample Im-porphyrin - CuTPP-CHO(NO $\left.\mathrm{NO}_{2}\right)$ possesses the highest antimicrobial activity at $2.33 \cdot 10^{-3} \mathrm{M}$ concentration (Figure 6). Probably, the culture of Candida Albicans, is more dependent on the concentration of nitro-porphyrin than on the presence of metal in the porphyrin core.

\section{Conclusion}

We have developed a mild method for electrophilic nitration of the phenyl groups of $\mathrm{H}_{2}$ TPP (1a) and $\mathrm{H}_{2}$ TPP$\mathrm{CHO}(3)$. It was shown that the most efficient nitration system is a mixture of trifluoroacetic acid and sodium nitrite.

The obtained meso-nitrophenyl- $\beta$-formylporphyrin (4a) and its $\mathrm{Cu}$ complex (4b) were immobilized on polyvinyl alcohol and antibacterial action of the obtained PPIm system was studied. It was shown that the presence of metal in the coordination center of porphyrin fragment and the PPIm concentration influence greatly on the growth or inhibition of bacterial culture.

Acknowledgments. This work was financially supported by grants of Russian Foundation for Basic Research 09-0300927 and 11-03-01000, and by program "Scientific and scientific-pedagogical personnel of innovative Russia for 2009-2012” St. № 02.740.11.0106.

\section{Staphylococcus aureus}

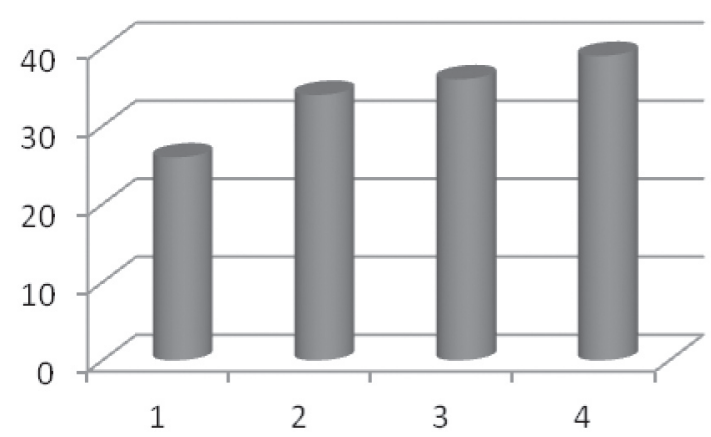

Figure 6. Effect of immobilized CuTPP-CHO(NO $\left.\mathrm{N}_{2}\right)$ on the Staphylococcus aureus inhibition at various concentrations of PPIm: $0.35 \cdot 10^{-3} \mathrm{M}(1), 0.5 \cdot 10^{-3} \mathrm{M}(2), 0.98 \cdot 10^{-3} \mathrm{M}(3)$ and $2.33 \cdot 10^{-3}(4)$.

\section{References}

1. Porfiriny: Spektroskopiya, Elektrokhimiya, Primenenie [Porphyrins: Spectroscopy, Electrochemistry, Application], Moskva: Nauka. 1987, 214 (in Russ).

2. Koifman O.I., Ageeva T.A. Porfirinpolimery [Porphyrinpolymers], Moskva: IFML. 2006, 194 (in Russ).

3. Ageeva T.A., Syrbu S.A., Koifman O.I. Macroheterocycles 2009, 2, 139-150.

4. Frankevich E.L., Busheva L.I., Cherkashina L.E., Balabanov E.I. Vysokomol. Soedin. 1964, 6, 1028 (in Russ.).

5. Makarov K.A., Kibardin S.A. Immobilizovannye Biopreparaty $v$ Medicine. [Immobilized Biologics in Medicine], Moskva: Medicina. 1980, 126 (in Russ).

6. Triven M. Immobilizovannye Fermenty [Immobilized Enzymes], Moskva: Mir. 1983, 213 p. (in Russ).

7. Hartli F. Zakreplennye Metallokompleksy [Immobilized Metal Complexes], Moskva: Mir, 1989, 360 p. (in Russ).

8. Traven V.F. Organicheskaya Khimiya [Oganic Chemistry], Moskva: Nauka. 2004, 130 p. (in Russ).

9. Alopina E.V., Ageeva T.A., etc. Izv. Vyssh. Uchebn. Zaved., Khim. Khim. Tehnol. 2011, 54(12), 81-85 (in Russ).

10. Afinogenov G.E., Panarin E.F. Antimicrobnye Polimery [Antimicrobial Polymers], SPb: Gippokrat, 1993. 264 p. (in Russ).

11. Bonfantini E.E., Burrel A.K., Campbell W.M., Crossley M.J., Gosper J.J., Harding M.M., Officer D.L., Reid D.C.W. J. Porphyrins Phthalocyanines 2002, 6, 708-719. 